\title{
Neoadjuvant imatinib in patients with locally advanced non metastatic GIST in the prospective BFR14 trial
}

\author{
Aurore Blesius ${ }^{1 \dagger}$, Philippe A Cassier ${ }^{2^{*}}$, François Bertucci ${ }^{3}$, Jerome Fayette ${ }^{2}$, Isabelle Ray-Coquard ${ }^{2}$, Binh Bui ${ }^{4}$, \\ Antoine Adenis ${ }^{5}$, Maria Rios ${ }^{6}$, Didier Cupissol ${ }^{7}$, David Pérol ${ }^{8}$, Jean-Yves Blay ${ }^{2}$, Axel Le Cesne ${ }^{1}$
}

\begin{abstract}
Background: The role of surgery in the management of patients with advanced gastrointestinal stromal tumors (GIST) in the era of imatinib mesylate (IM) remains debated. We analyzed the outcome of patients with non metastatic locally advanced primary GIST treated with IM within the prospective BFR14 phase III trial.

Methods: The database of the BFR14 trial was searched for patients with no metastasis at time of inclusion. Patients treated for recurrent disease were excluded. Twenty-five of 434 patients met these criteria.

Results: Fifteen of 25 patients (60\%) had a partial response to IM. Nine of the 25 patients (36\%) underwent surgical resection of their primary tumor after a median of 7.3 months of IM treatment (range 3.4-12.0). Per protocol patients received continuous IM treatment in the post resection period, in an adjuvant setting. With a median follow-up of 53.5 months, there was a significant improvement in progression-free survival (PFS) and overall survival (OS) for patients who underwent surgical resection versus those who did not (median not reached vs 23.6 months, $p=0.0318$ for PFS and median not reached vs 42.2 months, $p=0.0217$ for OS). In the group of patients who underwent resection followed by IM, the 3-year PFS and OS rates were $67 \%$ and $89 \%$ respectively

Conclusions: Following neoadjuvant IM for non metastatic locally advanced GIST 9 of 25 patients (36\%) were selected for resection of the primary tumor. OS and PFS figures were close to those of localised intermediate or high risk GIST (70\% at 5 years) in the subgroup of operated patients, while the outcome of the non-operated subgroup was similar to that of metastatic GIST.
\end{abstract}

\section{Background}

Gastrointestinal stromal tumors (GIST) are the most frequent mesenchymal tumors of the gastrointestinal tract and are thought to originate from the interstitial cells of Cajal [1]. The management of advanced and metastatic GIST has considerably improved with the use of imatinib mesylate (IM). Approximately 50 to $70 \%$ of unselected patients with advanced or metastatic GIST respond to IM and the median progression-free survival (PFS) is 20 to 24 months $[1,2]$ in a highly chemo-resistant disease [3]. IM, originally designed as a specific inhibitor of the $\mathrm{Bcr}-\mathrm{Abl}$ kinase for the treatment of chronic myelogenous

\footnotetext{
* Correspondence: cassierp@hotmail.com

† Contributed equally

2Department of medicine, Centre Léon Bérard, 28 rue Laennec, 69008 Lyon, France

Full list of author information is available at the end of the article
}

leukaemia, was also shown to be a potent inhibitor of the tyrosine kinase activities of KIT, PDGFR and CSF1R. KIT or PDGFRA mutations are considered an early event in the oncogenesis of GIST $[4,5]$ and are found in roughly $90 \%$ of cases. IM is considered a standard of care for patients with advanced disease and as adjuvant therapy for completely resected localised GIST [6-8]; however, its role in the neoadjuvant setting is currently under investigation.

The outcome of patients with locally advanced and unresectable GIST is generally considered to be similar to that of patients with metastatic disease. Although first-line treatment with IM produces high rates of disease control in patients with advanced disease, most patients experience disease progression due to the emergence of molecularly resistant clones within 2-3 years
C Biomed Central

() 2011 Blesius et al; licensee BioMed Central Ltd. This is an Open Access article distributed under the terms of the Creative Commons Attribution License (http://creativecommons.org/licenses/by/2.0), which permits unrestricted use, distribution, and reproduction in any medium, provided the original work is properly cited. 
after treatment initiation. This observation led several authors to investigate the value of surgical excision of residual disease following response to IM, before the development of secondary resistance. Several publications have reported on the feasibility of surgery following primary treatment with IM [9-14], but little is known about the exact benefit in terms of progressionfree or overall survival. Furthermore, all these studies included patients with both locally advanced and metastatic disease. All were retrospective, except the recently reported RTOG-0132 study [11].

We report here the retrospective analysis of patients with locally advanced non metastatic GIST who received primary medical therapy with IM in the BFR14 prospective trial [15], with special attention to the patients who underwent secondary surgery of their primary tumor.

\section{Methods \\ BFR14 population}

The BFR14 trial is a phase III trial randomizing interruption versus continuation of imatinib beyond one year of treatment for non progressive patients [15]. After the results of the randomisation at one year were known, the protocol was amended to allow randomisation after three years of treatment, and more recently after five years of treatment [16].

Inclusion criteria were: age at least 18 years, histological confirmation of locally advanced and/or metastatic GIST, immunohistochemical documentation of c-KIT (CD117) expression, and Eastern Cooperative Oncology Group performance status of 0 to 3 . Patients had to be previously untreated with imatinib, with no history of previous malignancy, and were required to have normal renal, cardiac, and hepatic functions. No concurrent anticancer therapy was allowed. All patients gave written informed consent before inclusion.

Imatinib was given orally at $400 \mathrm{mg}$ per day, as a single daily dosing. Clinical and biological tolerance was assessed weekly during the first month of treatment, every 2 weeks the following month, then monthly for three months, and every three months thereafter. Initial assessment included a complete history, clinical examination, serum biochemistry, liver function test, whole blood count and computed tomography scan (CT scan) and/or magnetic resonance imaging (MRI) of the tumor. Imaging techniques were repeated after 6 and 12 weeks of treatment and every 3 month thereafter. Response was graded according to the RECIST criteria [17].

\section{Definition of non metastatic locally advanced GIST}

To be eligible for the present substudy, patients of the BFR14 study were to have primary non metastatic GIST as assessed by the local multidisciplinary team at each participating site, and no prior surgery, thus excluding patients with recurrent GIST.

\section{Statistical analysis}

Data were described using the median and range for continuous variables and using percentages with 95\% confidence intervals for qualitative variables. Comparisons were performed using the chi-square test, Fisher's exact test, or Wilcoxon's rank-sum test as appropriate. Survival times were calculated from the date of entry in the BFR14 trial (i.e. initiation of IM treatment) and were displayed using the Kaplan-Meier method [18]. Progression-free survival (PFS) was defined as the time from the date of inclusion (start of IM) to the date of progression on IM $400 \mathrm{mg} /$ day or death. Overall survival (OS) was defined as the time from the date of inclusion to death of any cause. Differences in survival distributions were tested using the Log-Rank test. Differences were considered statistically significant when $\mathrm{p} \leq 0.05$. Statistical analyses were performed using the SPSS 12.0.1 (SPSS Inc, Chicago, IL) software package.

\section{Results}

As of April 2010, 434 patients have been included in the BFR14 trial. Sixty patients were registered as having no known metastasis initially. Of these 60 patients, only 25 had no previous history of surgery for GIST and were included in the present substudy. The 35 remaining cases included patients with locally advanced disease who received IM as additional therapy following R2 resection or patients with locally advanced recurrent disease.

Characteristics of these 25 patients and response to IM are presented in Table 1. Median age was 65.5 (range 39.8-80.5) years, 16 patients were males and the median performance status was 1 (range 0-3). Median tumor size at baseline was $15 \mathrm{~cm}$. No complete response was seen following treatment with IM, 15 patients (60\%) had a partial response (PR) after a median of 4.0 (range 1.4-12.8) months, 7 patients (28\%) had stable disease (SD) as their best response, while $3(12 \%)$ patients had progressive disease (PD) as their best response (Figure 1).

Nine of the 25 patients (38\%) underwent surgery after a median of 7.3 (range 3.4-12.0) months of IM treatment. Surgery was performed by the local surgeons who had initially refuted operation. In 4 patients tumor shrinkage with IM allowed resection at the price of a less morbid operation. In 2 patients surgical resection was performed as a salvage procedure for disease progressing on IM (primary progession in one case and progression following initial response in another case). The reason(s) that lead to the decision to operate each patient are listed in table 2. Patients who underwent 


\begin{tabular}{|c|c|c|c|c|c|c|}
\hline \multirow[b]{2}{*}{ Characteristics } & \multicolumn{2}{|c|}{ All } & \multicolumn{2}{|c|}{$\begin{array}{c}\text { Patients who } \\
\text { underwent surgery }\end{array}$} & \multicolumn{2}{|c|}{$\begin{array}{l}\text { Patients who } \\
\text { were operated }\end{array}$} \\
\hline & $\mathrm{N}$ & $\%$ & $\mathrm{~N}$ & $\%$ & $\mathrm{~N}$ & $\%$ \\
\hline & 25 & & 9 & & 16 & \\
\hline \multicolumn{7}{|l|}{ Age } \\
\hline $\begin{array}{l}\text { Median } \\
\text { (range) }\end{array}$ & $\begin{array}{c}65.5 \\
(39.8-80.5)\end{array}$ & & $\begin{array}{c}60.0 \\
(39.8-80.5)\end{array}$ & & $\begin{array}{c}69.7 \\
(40.7-81.9)\end{array}$ & \\
\hline \multicolumn{7}{|l|}{ Gender } \\
\hline Male & 16 & $64 \%$ & 6 & $67 \%$ & 10 & $63 \%$ \\
\hline Female & 9 & $36 \%$ & 3 & $33 \%$ & 6 & $38 \%$ \\
\hline Tumor location & & & & & & $0 \%$ \\
\hline Stomach & 4 & $16 \%$ & 1 & $11 \%$ & 3 & $19 \%$ \\
\hline Small intestine & 7 & $28 \%$ & 4 & $44 \%$ & 3 & $19 \%$ \\
\hline Peritoneum & 7 & $28 \%$ & 1 & $11 \%$ & 6 & $38 \%$ \\
\hline Oesophagus & 2 & $8 \%$ & 0 & $0 \%$ & 2 & $13 \%$ \\
\hline Rectum & 4 & $16 \%$ & 3 & $33 \%$ & 1 & $6 \%$ \\
\hline Pelvis & 1 & $4 \%$ & 0 & $0 \%$ & 1 & $6 \%$ \\
\hline \multicolumn{7}{|l|}{ Tumor size (mm) } \\
\hline Median (range) & 150 & $(36-280)$ & 150 & $(45-280)$ & 149 & $(36-200)$ \\
\hline$\leq 50$ & 2 & $8 \%$ & 1 & $11 \%$ & 1 & $6 \%$ \\
\hline $50<-\leq 100$ & 7 & $28 \%$ & 3 & $33 \%$ & 4 & $25 \%$ \\
\hline$>100$ & 16 & $64 \%$ & 5 & $56 \%$ & 11 & $69 \%$ \\
\hline WHO PS & & & & & & $0 \%$ \\
\hline 0 & 10 & $40 \%$ & 4 & $44 \%$ & 6 & $38 \%$ \\
\hline 1 & 10 & $40 \%$ & 5 & $56 \%$ & 5 & $31 \%$ \\
\hline 2 & 2 & $8 \%$ & 0 & $0 \%$ & 2 & $13 \%$ \\
\hline 3 & 1 & $4 \%$ & 0 & $0 \%$ & 1 & $6 \%$ \\
\hline Not reported & 2 & $8 \%$ & 0 & $0 \%$ & 2 & $13 \%$ \\
\hline \multicolumn{7}{|l|}{ Best response to IM } \\
\hline $\mathrm{PR}$ & 15 & $60 \%$ & 6 & $67 \%$ & 9 & $56 \%$ \\
\hline SD & 7 & $28 \%$ & 2 & $22 \%$ & 5 & $31 \%$ \\
\hline PD & 3 & $12 \%$ & 1 & $11 \%$ & 2 & $13 \%$ \\
\hline
\end{tabular}

surgery tended to be younger (median 60.0 vs 69.7, $\mathrm{p}=$ 0.174) and have better performance status (PS) (PS 0-1 $9 / 9$ vs $11 / 16, \mathrm{p}=0.253)$ than the non-operated patients, although these differences were not statistically different (table 1). The sex ratio was similar between the two groups. Non-operated patients were more likely to have GIST from the peritoneum or the oesophagus (7/16 vs $1 / 9, p=0.040)$. Baseline tumor size was comparable between patients who were operated and those who were not $(p=0.671$, Mann and Whitney test $)$. The response rate was slightly superior in the operated group (67\% vs $56 \%$ in the non-operated group), but the difference was not statistically significant $(\mathrm{p}=0.691)$. The clinical benefit rate $(\mathrm{PR}+\mathrm{SD})$ was similar in the two groups $(89 \%$ and $88 \%, \mathrm{p}=1.0)$. Among the 9 patients who underwent surgery, 6 had a partial response after a median of 4.2 months of treatment with IM, and surgery was microscopically complete (R0) for 5 of them and macroscopically incomplete in one of them (R2). Two patients underwent surgery with a volumetric response which was less than a partial response, i.e. disease stabilization according to RECIST; and surgery was complete for both of them (R0). One patient underwent surgery while his disease was progressing according to RECIST: surgical excision was macroscopically complete but with positive margins, and this patient remains in complete response (CR) 66.4 months after the procedure despite his refusal to continue IM post-operatively. The other eight operated patients accepted to continue IM after surgery as specified by the study protocol. Three of 9 patients progressed 13.3, 17.0 and 24.8 months after surgery; the other 6 patients are currently in CR at a median of 55.4 (range 50.0-66.5) months after surgery.

With a median follow-up of 53.5 (range 4.4-77.0) months, the median PFS is 32.1 months for the 25 patients (Figure 2), while median OS is not reached (not shown). PFS was significantly longer (figure 3 ) for the 9 patients who underwent surgery after IM than for the 


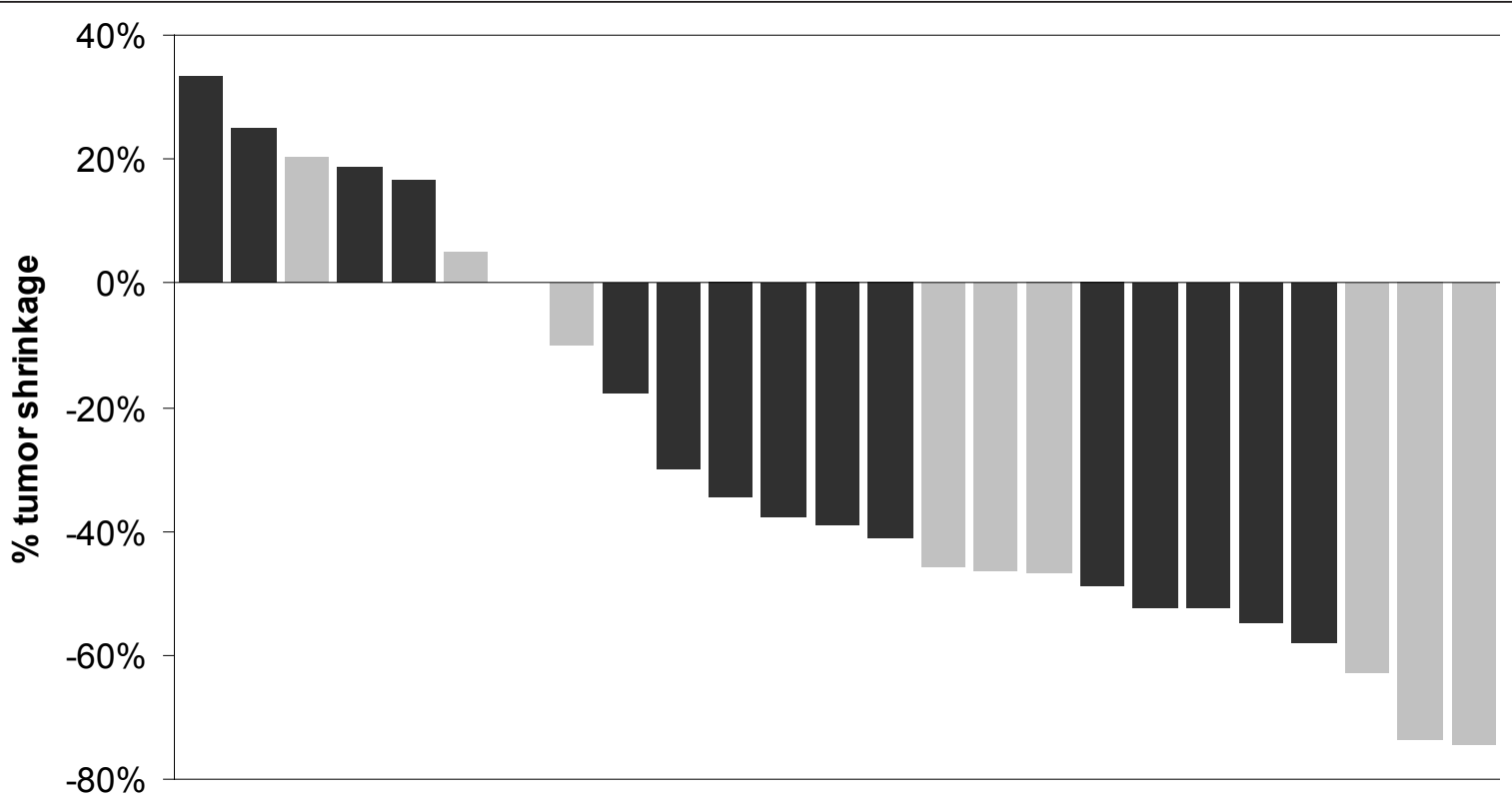

Figure 1 Waterfall plot of patients' best response. Dark grey bars represent patients who did not undergo resection of their primary tumor. Light grey bars represent patient who had their primary tumor resected.

16 patients who continued medical treatment alone (median PFS not reached vs 23.6 months respectively, $\mathrm{p}=0.0322$ ). Similarly, OS (figure 4) was longer for the resected group (median OS not reached $v s 29.7$ months respectively, $\mathrm{p}=0.0154)$. This difference in PFS and OS persisted when analysis was limited to patients with PR or SD on IM, after exclusion of progressive patients, although the difference in PFS did not reach statistical significance in this analysis (median 29.7 vs not reached, $\mathrm{p}=0.0998$ and 42.2 vs not reached, $\mathrm{p}=0.0333$ for PFS and OS respectively). When analysing only the 15 patients who had PR to IM, the median PFS was 29.7 months for non-resected patients $v s$ not reached for resected patients $(\mathrm{p}=0.2829)$.

\section{Discussion}

Imatinib mesylate is the new paradigm of treatment targeting the initial causal molecular event in solid tumors. However, it is still unclear whether patients with locally advanced or metastatic disease are cured, as shown by the results of the BFR14, which showed consistent disease progression following treatment interruption after 1,3 and 5 years of treatment $[15,16]$. The role of surgery during or following treatment with IM for locally

Table 2 Reasons for operation following treatment with Imatinib

\begin{tabular}{|c|c|c|c|c|c|}
\hline $\begin{array}{l}\text { Patient } \\
\mathrm{N}\end{array}$ & $\begin{array}{l}\text { Age at } \\
\text { surgery }\end{array}$ & $\begin{array}{l}\text { Tumor } \\
\text { location }\end{array}$ & $\begin{array}{c}\text { Best \% } \\
\text { tumor } \\
\text { shrikage }\end{array}$ & $\begin{array}{l}\text { Time to } \\
\text { surgery }\end{array}$ & reason for operation \\
\hline 4 & 43 & Rectum & -47 & 12,1 & Significant response after 12 months on imatinib, enabling tumor resection \\
\hline 6 & 66 & Mesentery & -63 & 6,7 & Large tumor lesion, decision to operate following tumor shrinkage on imatinib \\
\hline 7 & 81 & Rectum & -47 & 8,1 & $\begin{array}{l}\text { After initial response, patient had early signs of progression (increased blood flow on } \\
\text { DCE-ultrasound) and was therefore operated before actual RECIST progression }\end{array}$ \\
\hline 8 & 40 & Rectum & -46 & 7,3 & Surgery enabled following tumor shrinkage \\
\hline 12 & 43 & $\begin{array}{l}\text { Small } \\
\text { bowel }\end{array}$ & -74 & 6,5 & Surgery planned prior to treatment with imatinib (true neoadjuvant) \\
\hline 13 & 61 & $\begin{array}{l}\text { Small } \\
\text { bowel }\end{array}$ & -74 & 11,7 & Surgery enabled following tumor shrinkage \\
\hline 14 & 71 & $\begin{array}{l}\text { Small } \\
\text { bowel }\end{array}$ & 20 & 3,4 & $\begin{array}{l}\text { Rapid progression on imatinib } 400 \mathrm{mg} / \mathrm{d} \text {, dose increased to } 600 \mathrm{mg} / \mathrm{d} \text { which was } \\
\text { poorly tolerated, salvage surgery seemed feasible. Resection was R1 }\end{array}$ \\
\hline 15 & 76 & Stomach & 5 & 4,4 & $\begin{array}{l}\text { No response on imatinib with poor tolerance. Following surgery this patient was } \\
\text { restarted on a lower dose of IM. }\end{array}$ \\
\hline 16 & 50 & $\begin{array}{l}\text { Small } \\
\text { bowel }\end{array}$ & -19 & 7,3 & Stable disease after 6 months on imatinib, surgery was deemed feasible by surgeon. \\
\hline
\end{tabular}




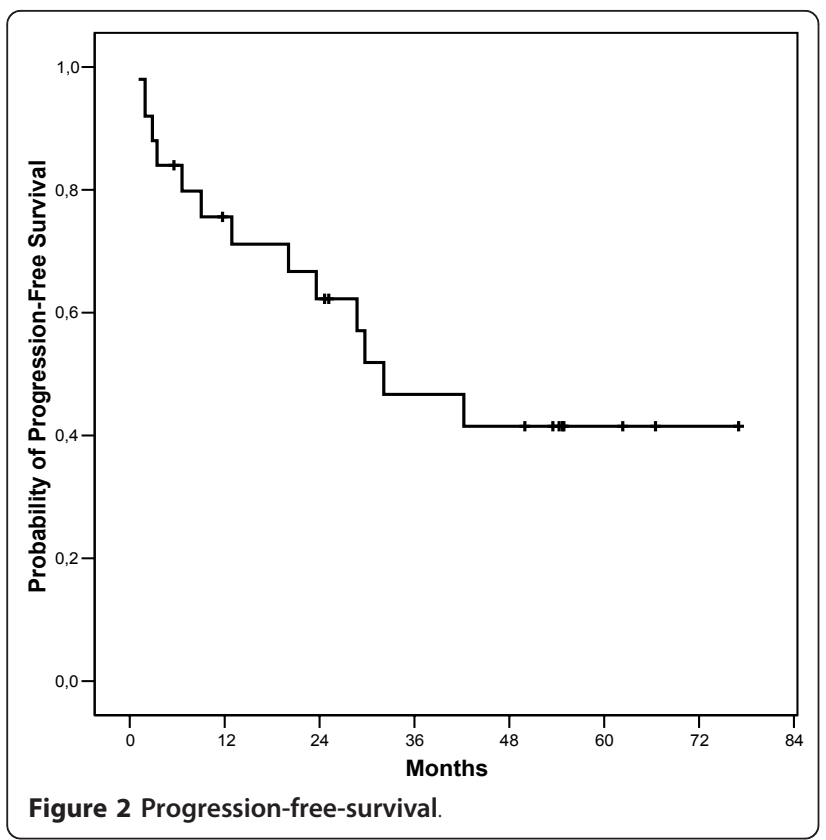

advanced disease remains controversial. Several expert centers throughout the world have reported their results with surgical resection following treatment with IM for both locally advanced and metastatic GIST [9-14]. All these studies are unicentric and retrospective. Most of them have underlined the strong correlation between the disease status regarding response to IM before surgery and the outcome after surgery. Patient with multifocal progressive disease at the time of surgery have a short PFS following surgery (3-6 months), while patients

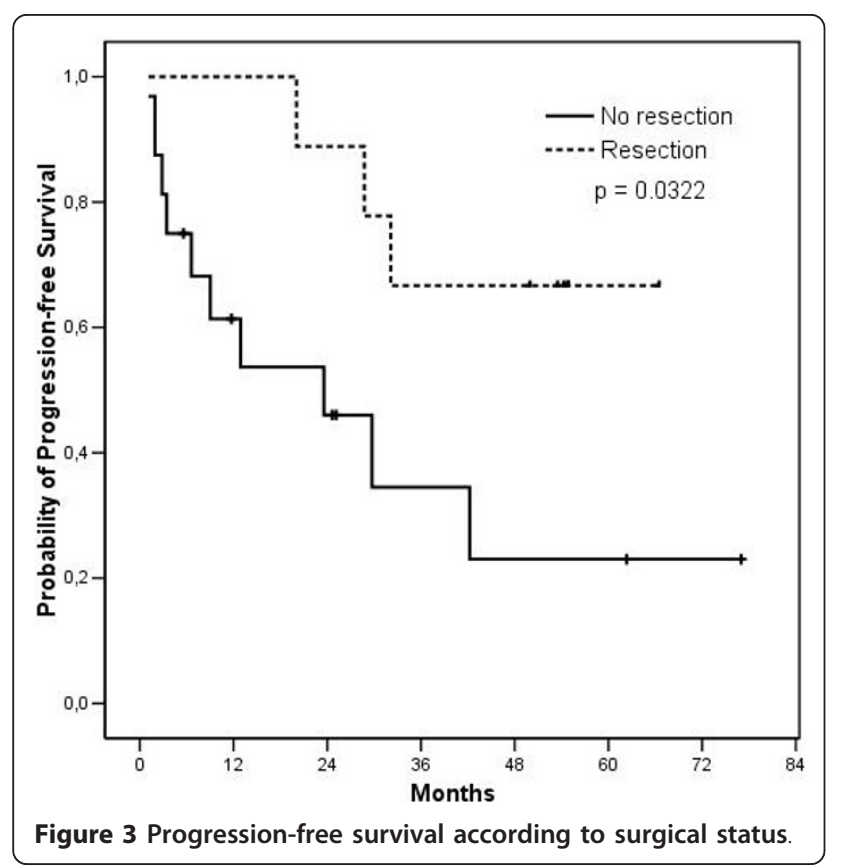

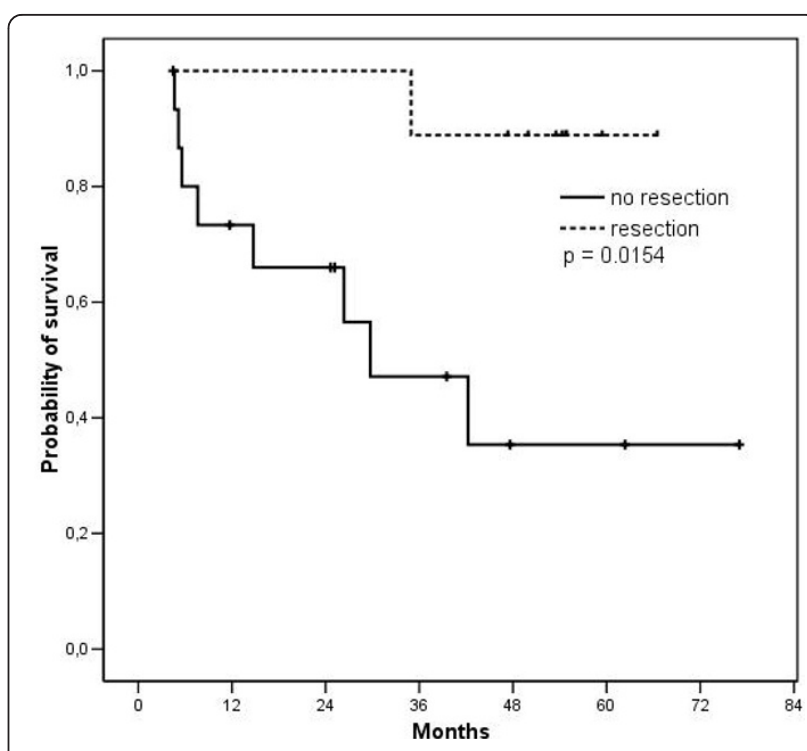

Figure 4 Overall survival according to surgical status.

with unifocal disease progression have a 6 months median PFS with some patients remaining free of progression after long-term follow-up [12,13]. The recently reported RTOG0132/ACRIN6665 trial [11] is the first study to prospectively assess the role of preoperative IM (during 8 to 12 weeks) in patients with primary locally advanced ( $\geq 5 \mathrm{~cm}: 30$ patients) and/or metastatic/recurrent ( $\geq 2 \mathrm{~cm}: 20$ patients) GIST. In this study, toxicity was minimal and did not modify post-operative morbidity. However, because it was a single arm phase II trial, this study did not answer the question of the benefit of surgery in patients with locally advanced initially inoperable GIST.

Our present study is the first multi-centric series to address the issue of benefit of surgery after neoadjuvant IM in this setting. We show that among 25 patients with non-metastatic locally advanced GIST, 9 patients (36\%) were selected to undergo surgical resection following primary medical treatment with IM. These 9 patients had improved PFS and OS compared to nonoperated patients, with survival rates close to those observed for localised intermediate or high risk GIST, whereas survival of non-operated patients was similar to that of patients with metastatic disease. Although these results suggest an improved outcome for operated patients, this study has some obvious limitations. One of these limitation is that patients were selected and not randomised to undergo surgery and were therefore more likely to benefit from the procedure based on medical judgement by the investigators at each site. Furthermore, our series is small and retrospective, precluding any definitive conclusion. As previously mentioned our observation is likely biased since selection of 
patients for surgery may be linked to other prognostic factors such as tumor location, patient's age, performance status as reflected by the differences (though not significant) seen in our series between the operated and non-operated groups. The response to IM may be another source of bias as more patients had a PR in the operated group than in the non-operated group. However, survival remained better in the operated group even when considering only patients with partial response or patients with clinical benefit (PR or SD). A possible source of difference of survival between the two groups may be the randomisation (see the "patients and methods" section). Six of 25 patients were randomised, two in the IM continuation arm and four in the interruption arm. All of the four patients randomised to interruption were in the non surgical group, therefore introducing a bias. However, PFS and OS were still significantly better in the surgery group when these four cases were removed from analysis $(9.0$ months $v s$ median not reached $\mathrm{p}=0.0037$ and 26.3 months $v s$ median not reached, $\mathrm{p}=0.0128$ respectively for PFS and OS).

Another bias source of this multicentric study lies in the inclusion criterion of initial unresectability, which was left at the treating physician's discretion. Therefore, some patients may have had truly unresectable disease, while others may have had disease that was actually resectable at the price of a major procedure, in which case primary medical treatment appeared to be the best option. Resectability, before and after IM, was assessed by multidisciplinary teams, including surgeons expert in GIST management.

\section{Conclusions}

Overall, this and other reports can not lead to any definitive conclusion regarding the benefit of surgery in patients with locally advanced GIST treated with IM. This benefit can only be demonstrated in randomised prospective trials, which are ongoing in the metastatic setting. However, since patients with locally advanced disease who become operable following IM appear to benefit from resection of the primary tumor, we think that surgery should be proposed, or at least discussed, in this subgroup of patients when the disease no longer responds to IM.

\section{Acknowledgements}

The BFR14 trial was funded by a research grant from Novartis (Basel, Switzerland)

\footnotetext{
Author details

1Department of medicine, Institut Gustave Roussy, 39 bis rue Camille Desmoulins, 94800 Villejuif, France. ${ }^{2}$ Department of medicine, Centre Léon Bérard, 28 rue Laennec, 69008 Lyon, France. ${ }^{3}$ Department of medicine, Institut Paoli-Calmettes, 232 boulevard Sainte Marguerite, 13009 Marseille, France. ${ }^{4}$ Department of medicine, Institut Bergonié, 229 cours Argonne, 33000 Bordeaux, France. ${ }^{5}$ Department of medicine, Centre Oscar Lambret,
}

3 rue Frederic Combemale, 59000 Lille, France. ${ }^{6}$ Department of medicine, Centre Alexis Vautrin, 6 avenue Bourgogne, 54500 Vandoeuvre-lès-Nancy, France. ${ }^{7}$ Department of medicine, Centre Val d'Aurelle, 31 rue Croix Verte, 34000 Montpellier, France. ${ }^{8}$ Department of biostatistics, Centre Léon érard, 28 rue Laennec, 69008 Lyon, France.

\section{Authors' contributions}

$A B$ contributed to provision of patients, participated in data acquisition, analysed the data, and helped draft the manuscript; PAC designed the study, contributed to patient provision, participated in data acquisition, analysed the data, and drafted the manuscript; FB contributed to patient provision and helped draft the manuscript; JF designed the study and contributed to patient provision; IRC and BB, AA contributed to patient provision and helped draft the manuscript, MR and DC contributed to provision of patients; DP contributed to the design of the BFR14 study and participated in data acquisition; JYB and AL contributed to the design of the BFR14 study, to patient provision and helped draft the manuscript. All authors have read and approved the final manuscript.

\section{Competing interests}

The authors declare that they have no competing interests.

Received: 22 October 2010 Accepted: 15 February 2011

Published: 15 February 2011

\section{References}

1. Demetri GD, von MM, Blanke CD, Van den Abbeele AD, Eisenberg B, Roberts PJ, et al: Efficacy and safety of imatinib mesylate in advanced gastrointestinal stromal tumors. N Engl J Med 2002, 347:472-480.

2. Verweij J, Casali PG, Zalcberg J, Lecesne A, Reichardt P, Blay JY, et al: Progression-free survival in gastrointestinal stromal tumours with highdose imatinib: randomised trial. Lancet 2004, 364:1127-1134.

3. Cassier PA, Dufresne A, Arifi S, El SH, Labidi I, Ray-Coquard I, et al: Imatinib mesilate for the treatment of gastrointestinal stromal tumour. Expert Opin Pharmacother 2008, 9:1211-1222.

4. Hirota S, Isozaki K, Moriyama Y, Hashimoto K, Nishida T, Ishiguro S, et al: Gain-of-function mutations of c-kit in human gastrointestinal stromal tumors. Science 1998, 279:577-580.

5. Heinrich MC, Corless CL, Duensing A, McGreevey L, Chen CJ, Joseph N, et al: PDGFRA activating mutations in gastrointestinal stromal tumors. Science 2003, 299:708-710.

6. Demetri GD, Benjamin RS, Blanke CD, Blay JY, Casali P, Choi H, et al: NCCN Task Force report: management of patients with gastrointestinal stromal tumor (GIST)-update of the NCCN clinical practice guidelines. J Natl Compr Canc Netw 2007, 5(Suppl 2):S1-29, quiz S30.

7. Casali PG, Jost L, Reichardt P, Schlemmer M, Blay JY: Gastrointestinal stromal tumors: ESMO clinical recommendations for diagnosis, treatment and follow-up. Ann Oncol 2008, 19(Suppl 2):ii35-ii38.

8. Dematteo RP, Ballman KV, Antonescu CR, Maki RG, Pisters PW, Demetri GD et al: Adjuvant imatinib mesylate after resection of localised, primary gastrointestinal stromal tumour: a randomised, double-blind, placebocontrolled trial. Lancet 2009, 373:1097-1104

9. Andtbacka RH, Ng CS, Scaife CL, Cormier JN, Hunt KK, Pisters PW, et al: Surgical resection of gastrointestinal stromal tumors after treatment with imatinib. Ann Surg Oncol 2007, 14:14-24

10. Bonvalot $\mathrm{S}$, Eldweny $\mathrm{H}$, Pechoux $\mathrm{CL}$, Vanel $\mathrm{D}$, Terrier $\mathrm{P}$, Cavalcanti $\mathrm{A}$, et al: Impact of surgery on advanced gastrointestinal stromal tumors (GIST) in the imatinib era. Ann Surg Oncol 2006, 13:1596-1603.

11. Eisenberg BL, Harris J, Blanke CD, Demetri GD, Heinrich MC, Watson JC, et al: Phase II trial of neoadjuvant/adjuvant imatinib mesylate (IM) for advanced primary and metastatic/recurrent operable gastrointestinal stromal tumor (GIST): early results of RTOG 0132/ACRIN 6665. J Surg Oncol 2009, 99:42-47.

12. Gronchi A, Fiore M, Miselli F, Lagonigro MS, Coco P, Messina A, et al: Surgery of residual disease following molecular-targeted therapy with imatinib mesylate in advanced/metastatic GIST. Ann Surg 2007, 245:341-346.

13. Raut CP, Posner M, Desai J, Morgan JA, George S, Zahrieh D, et al: Surgical management of advanced gastrointestinal stromal tumors after treatment with targeted systemic therapy using kinase inhibitors. J Clin Oncol 2006, 24:2325-2331. 
14. Rutkowski P, Nowecki Z, Nyckowski P, Dziewirski W, Grzesiakowska U, Nasierowska-Guttmejer A, et al: Surgical treatment of patients with initially inoperable and/or metastatic gastrointestinal stromal tumors (GIST) during therapy with imatinib mesylate. J Surg Oncol 2006, 93:304-311.

15. Blay JY, Le CA, Ray-Coquard I, Bui B, Duffaud F, Delbaldo C, et al: Prospective multicentric randomized phase III study of imatinib in patients with advanced gastrointestinal stromal tumors comparing interruption versus continuation of treatment beyond 1 year: the French Sarcoma Group. J Clin Oncol 2007, 25:1107-1113.

16. Le Cesne A, Ray-Coquard I, Bui B, Rios M, Adenis A, Bertucci F, et al: Continuous versus interruption of imatinib (IM) in responding patients with advanced GIST after three years of treatment: A prospective randomized phase III trial of the French Sarcoma Group. J Clin Oncol (Meeting Abstracts) 2007, 25:10005.

17. Therasse P, Arbuck SG, Eisenhauer EA, Wanders J, Kaplan RS, Rubinstein L, et al: New guidelines to evaluate the response to treatment in solid tumors. European Organization for Research and Treatment of Cancer, National Cancer Institute of the United States, National Cancer Institute of Canada. J Natl Cancer Inst 2000, 92:205-216.

18. Kaplan EL, Meier P: Nonparametric estimation from incomplete observations. J Am Stat Assoc 1958, 53:457-481.

\section{Pre-publication history}

The pre-publication history for this paper can be accessed here: http://www.biomedcentral.com/1471-2407/11/72/prepub

doi:10.1186/1471-2407-11-72

Cite this article as: Blesius et al.: Neoadjuvant imatinib in patients with locally advanced non metastatic GIST in the prospective BFR14 trial.

BMC Cancer 2011 11:72.

\section{Submit your next manuscript to BioMed Central and take full advantage of:}

- Convenient online submission

- Thorough peer review

- No space constraints or color figure charges

- Immediate publication on acceptance

- Inclusion in PubMed, CAS, Scopus and Google Scholar

- Research which is freely available for redistribution

Submit your manuscript at www.biomedcentral.com/submit 